\title{
Cell surface expression of adhesins for fibronectin correlates with virulence in Sporothrix schenckii
}

\author{
Pedro Antônio Castelo Teixeira, ${ }^{1}$ Rafaela Alves de Castro, ${ }^{1}$ \\ Rosana Cícera Nascimento, ${ }^{1,2}$ Guy Tronchin, ${ }^{3}$ Armando Pérez Torres, ${ }^{4}$ \\ Márcia Lazéra, ${ }^{5}$ Sandro Rogério de Almeida, ${ }^{2}$ Jean-Philippe Bouchara, ${ }^{3,6}$ \\ Carla Veronica Loureiro y Penha ${ }^{1}$ and Leila M. Lopes-Bezerra ${ }^{1}$
}

Correspondence

Leila M. Lopes Bezerra

leila.lopes_bezerra@pq.cnpq.br

Received 18 March 2009

Revised 29 June 2009

Accepted 18 August 2009

\author{
${ }^{1}$ Departamento de Biologia Celular, Instituto de Biologia Roberto Alcantara Gomes, Universidade do \\ Estado do Rio de Janeiro, Brazil \\ ${ }^{2}$ Departamento de Análises Clínicas e Toxicológicas - Faculdade de Ciências Farmacêuticas, \\ Universidade de São Paulo, Brazil \\ ${ }^{3}$ Groupe d'Étude des Interactions Hôte-Pathogène, UPRES-EA 3142, Université d'Angers, Angers, \\ France \\ ${ }^{4}$ Laboratorio de Inmunología Comparada de Piel y Mucosas, Facultad de Medicina, Universidad \\ Nacional Autónoma de México, Mexico \\ ${ }^{5}$ Instituto de Pesquisa Clínica Evandro Chagas Filho - Fiocruz, Rio de Janeiro, Brazil \\ ${ }^{6}$ Laboratoire de Parasitologie-Mycologie, Centre Hospitalier Universitaire, Angers, France
}

The virulence of four Sporothrix schenckii isolates was compared in a murine model of sporotrichosis, together with the protein pattern of the yeast cell surface and the capacity to bind the extracellular matrix protein fibronectin. Virulence was determined by the mortality rate, fungal burden and histopathology. Two clinical isolates were more virulent for C57BL/6 mice, but no direct correlation was seen between virulence and the clinical or environmental origin of the isolates. The lowest virulence was observed for an isolate recovered from a patient with meningeal sporotrichosis. Although all isolates could effectively disseminate, the dissemination patterns were not similar. Using flow cytometry analysis, we investigated the interaction of all the strains with fibronectin, and showed that the binding capacity correlated with virulence. Western blot analysis of $S$. schenckii cell wall extracts revealed positive bands for fibronectin in the range of 37$92 \mathrm{kDa}$. The $70 \mathrm{kDa}$ adhesin was also recognized by a protective monoclonal antibody raised against a gp70 antigen of S. schenckii (mAb P6E7). Confocal microscopy confirmed the colocalization of fibronectin and mAb P6E7 on the yeast cell surface. To our knowledge, this is the first report identifying adhesins for fibronectin on the surface of this human pathogen.

\section{INTRODUCTION}

Sporothrix schenckii is the aetiological agent of sporotrichosis, an endemic deep mycosis in Latin America with several clinical presentations (Lopes-Bezerra et al., 2006). The most frequent clinical form is characterized by cutaneous and subcutaneous nodular lesions with lymphangitic involvement. The disseminated forms are less frequent and have been described mainly among immunocompromised patients (Lopes-Bezerra et al., 2006).

Some reports indicate that differences in clinical forms of sporotrichosis are due to host immunological disorders. The host immune response would thus determine the degree of fungal invasion (Maia et al., 2006). However,

Abbreviation: HRP, horseradish peroxidase. other studies report that variations in clinical presentations may also be explained by factors intrinsic to the pathogen, such as strain variations in thermotolerance or pathogenicity (Tachibana et al., 1998, 2001). Kong et al. (2006) suggested that some genotypes may be closely associated with $S$. schenckii virulence and infection outcome.

The capacity of a micro-organism to adhere to host cells and tissues is crucial for colonization and dissemination. Specific microbial adhesins mediate adherence to host tissues by participating in sophisticated interactions with some of the host proteins which compose the extracellular matrix. Fibronectin and laminin form part of the basal lamina, a sheet of molecules that underlies all epithelia and surrounds some nonepithelial cells in normal tissues. However, any type of trauma that damages the host tissues 
may expose the extracellular matrix and thus may enable microbial colonization and infection (Patti et al., 1994).

Our group previously reported that $S$. schenckii interacts with soluble and immobilized fibronectin; moreover, laminin and type II collagen were also reported as substrates for adherence of this pathogen (Lima et al., 1999, 2001, 2004). Study of independent isolates of Paracoccidioides brasiliensis revealed that the strains that were more virulent in animals exhibited enhanced adherence to extracellular matrix proteins in vitro (Hanna et al., 2000; Mendes-Giannini et al., 2006). However, to our knowledge such studies have never been conducted for S. schenckii.

In the present study, four isolates of S. schenckii were compared with regard to their virulence in a murine model of disseminated sporotrichosis and their capacity to interact with the extracellular matrix protein fibronectin. Adhesin expression on the yeast cell surface was also investigated.

\section{METHODS}

Micro-organism and culture conditions. Four isolates were used. Isolate 1099-18, which was obtained from the Mycology Section, Department of Dermatology, Columbia University, New York, USA, was originally recovered in the 1970s from a patient with subcutaneous sporotrichosis; isolates IPEC 15383 and IPEC 17943 were recovered in 1998 from a patient with disseminated cutaneous and osteoarticular sporotrichosis, and in 2000 from a HIV-positive patient with meningeal sporotrichosis, respectively. The environmental isolate FMR 8337 was collected in 2000 from domiciliary dust in Rio de Janeiro, Brazil.

The isolates were maintained by regular passages on animals, and were grown on Sabouraud dextrose agar (Difco) slants. The yeast form was obtained by cultivation in Brain Heart Infusion broth (Oxoid) at $37^{\circ} \mathrm{C}$ for 7 days in a rotary shaker (150 r.p.m.) as described previously (Fernandes et al., 2000).

The viability of the inocula of the four $S$. schenckii isolates was ascertained by c.f.u. counts after 7 days incubation on BHI agar plates at $37{ }^{\circ} \mathrm{C}$.

Mice. Male C57BL/6 isogenic mice 2 months old (weighing approximately $24 \mathrm{~g}$ ) were obtained from the Oswaldo Cruz Foundation (FIOCRUZ, Rio de Janeiro, Brazil). The mice were maintained in a specific pathogen-free environment and housed in temperature-controlled rooms at $23-25{ }^{\circ} \mathrm{C}$, with ad libitum access to food and water throughout the experiments. All procedures were approved by the Institutional Ethics Committee and were in accordance with National Institutes of Health Animal Care Guidelines.

Experimental infection. Groups of ten mice were inoculated intravenously with $5 \times 10^{6}$ yeast cells suspended in $0.1 \mathrm{ml}$ sterile PBS, as described by Fernandes et al. (2000). Control groups received the same volume of vehicle. The size of the inoculum was verified by plating an appropriate dilution of the yeast cell suspension and determination of the number of c.f.u. after 7 days incubation at $37^{\circ} \mathrm{C}$.

Infected and control mice were monitored daily for at least 45 days to determine the mortality rates. Fungal load in the spleen, lungs, liver and kidneys from individual mice was evaluated by determination of the number of c.f.u. Mice were sacrificed at day 10 post-infection and the organs were aseptically removed and weighed. Half of each sample was homogenized in sterile PBS. Samples $(50 \mu \mathrm{l})$ of each homogenate were plated onto BHI agar supplemented with penicillin G (10000 U $\mathrm{ml}^{-1}$ ) and streptomycin $\left(10000 \mu \mathrm{g} \mathrm{ml}^{-1}\right)$ (Gibco-BRL). Colonies were counted after incubation for 7 days and results are expressed as the number of c.f.u. per mg of tissue. In parallel, the other half of the specimens was fixed in $10 \%$ formaldehyde in PBS for histopathological examination.

Histopathology. Paraffin sections $(5 \mu \mathrm{m})$ of mouse liver were mounted on poly-L-lysine-coated slides and stained by a modification of Gomori's methenamine silver nitrate method (Grocott, 1955) or by the periodic acid/Schiff procedure (Prophet et al., 1992). Tissue sections were analysed using a single-blind method.

Flow cytometry. Binding of fibronectin (Invitrogen) to S. schenckii yeast cells was analysed by flow cytometry. Fibronectin was labelled with FITC (Sigma) as previously described (Lima et al., 2004). For the binding assays, $5 \times 10^{6}$ yeast cells of $S$. schenckii were incubated for $1 \mathrm{~h}$ at $37{ }^{\circ} \mathrm{C}$ under constant shaking with $100 \mu \mathrm{l}$ of a $100 \mu \mathrm{g} \mathrm{ml}{ }^{-1}$ FITC-labelled fibronectin solution. To assess the specificity of the binding, yeast cells were incubated with a 10 -fold excess of unlabelled fibronectin for $30 \mathrm{~min}$ prior to the addition of the labelled ligand. The cells were then washed, pelleted by centrifugation and fixed with $1 \%$ formaldehyde in PBS. Cell surface fluorescence was quantified using a FACScan flow cytometer (Becton-Dickinson Immunocytometry Systems Europe) equipped with an air-cooled $15 \mathrm{~mW}$ argon-ion laser operating at $488 \mathrm{~nm}$. The standard filter configuration was used for data acquisition. Cell debris was excluded by gating the fungal cells on the basis of their rectilinear forward and side light-scattering properties. Each sample was stored in a list mode file of 10000 events and the data were analysed using CELLQuest software from Becton Dickinson. The data presented correspond to fluorescence frequency distribution histograms (relative number of fungal cells versus relative fluorescence intensity expressed in arbitrary units on a logarithmic scale). All experiments were carried out at least twice and included a negative control performed by incubating the cells without any ligand to ascertain the absence of autofluorescence.

Generation of monoclonal antibody (mAb) and purification of gp70. $\mathrm{mAb}$ P6E7 was generated, according to the general procedure for generation of monoclonal antibodies (Köhler \& Milstein 1975), by immunization of 8 - to 12 -week-old $\mathrm{BALB} / \mathrm{c}$ mice inoculated intraperitoneally with the $70 \mathrm{kDa}$ glycoprotein from S. schenckii extracted from a preparative polyacrylamide gel, and by fusion of cells of the murine myeloma line SP $2 / \mathrm{O}$ with spleen cells from the mouse producing the highest polyclonal response as described by Nascimento et al. (2008).

gp70 was purified from yeast cell soluble antigen by affinity chromatography on mAb P6E7 immobilized on a CNBr-activated Sepharose column (Amersham Pharmacia) as described previously (Nascimento et al., 2008).

Preparation of cell wall extract. Cell wall protein extraction was performed as described by Klis et al. (2007). Briefly, yeast cells were collected, and washed with ice-cold $25 \mathrm{mM}$ Tris/ $\mathrm{HCl}, \mathrm{pH} 8.5$, the buffer used in the subsequent extraction step. Cells were further incubated with $2 \mathrm{mM}$ DTT in $25 \mathrm{mM}$ Tris/ $\mathrm{HCl}, \mathrm{pH} 8.5$, at $4{ }^{\circ} \mathrm{C}$ for $2 \mathrm{~h}$, with gentle agitation. The supernatant was then collected and concentrated and the proteins were precipitated by TCA/acetone for $1 \mathrm{~h}$ at $-20{ }^{\circ} \mathrm{C}$. The pellet was resuspended in water and lyophilized. Proteins were quantified by the 2-D Quant kit (Amersham Biosciences).

Western blot analysis. Proteins of $S$. schenckii cell wall extracts were separated by electrophoresis in $10 \%$ SDS-polyacrylamide gel as 
described by Laemmli (1970). The gels were stained by the silver method (Bjellqvist et al., 1993) and molecular mass was estimated using a $16-250 \mathrm{kDa}$ protein standard (Amersham Biosciences). To identify fibronectin-binding proteins, after electrophoresis the proteins were transferred to nitrocellulose membranes (Amersham Biosciences). Electroblotting was performed at $100 \mathrm{~V}$ for $120 \mathrm{~min}$ in

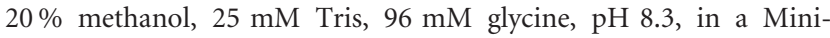
Protean II Cell (Bio-Rad). After transfer, the nitrocellulose was blocked with $5 \%$ skimmed milk in TTBS ( $50 \mathrm{mM}$ Tris, $0.15 \mathrm{M} \mathrm{NaCl}$, $0.1 \%$ Tween 20), washed in $1 \%$ skimmed milk in TTBS and incubated with fibronectin $\left(20 \mu \mathrm{g} \mathrm{ml}^{-1}\right)$ for $2 \mathrm{~h}$ at room temperature under constant agitation. The membrane was washed in TTBS-1\% skimmed milk, incubated with a rabbit anti-fibronectin immune serum, washed again and incubated with horseradish peroxidase (HRP)-conjugated anti-rabbit IgG antibodies. After washing, the nitrocellulose was developed with an ECL kit (ECL Rabbit IgG, HRPLinked Whole Ab, Amersham Biosciences). The same protocol as described above was used for affinity blotting experiments with the $\mathrm{mAb}$ P6E7. In this case, after the blocking step, membranes were incubated with the mAb P6E7 $\left(20 \mu \mathrm{g} \mathrm{ml}^{-1}\right)$ followed by incubation with HRP-conjugated anti-mouse IgG antibodies (Kirkegaard \& Perry Laboratories).

Confocal microscopy. The interaction of fibronectin with gp70 at the $S$. schenckii cell surface was analysed by confocal microscopy. To do this, $5 \times 10^{6}$ S. schenckii yeast cells were incubated with $100 \mu \mathrm{g}$ fibronectin $\mathrm{ml}^{-1}$ in PBS. After $1 \mathrm{~h}$ incubation at $37^{\circ} \mathrm{C}$ with gentle shaking, followed by three washes in PBS, the cells were incubated with a rabbit anti-fibronectin immune serum (Dako) at $20 \mu \mathrm{g} \mathrm{ml}^{-1}$ or with mAb P6E7 at $100 \mu \mathrm{g} \mathrm{ml}^{-1}$ in PBS supplemented with $1 \%$ BSA (PBS-BSA). The cell suspensions were then washed three times in PBS-BSA and stained for $1 \mathrm{~h}$ at $37^{\circ} \mathrm{C}$ with Alexa Fluor 568conjugated goat anti-rabbit IgG or Alexa Fluor 488-conjugated goat anti-mouse IgG antibodies (Molecular Probes) at $2 \mu \mathrm{g} \mathrm{ml}^{-1}$ in PBSBSA. Finally, yeast cells were washed with PBS, mounted on glass slides in PBS/glycerin $(1: 1, \mathrm{v} / \mathrm{v})$ and examined by confocal microscopy using an Olympus Fluview confocal microscope. For double labelling, cells were successively incubated with fibronectin, mAb P6E7, rabbit anti-human fibronectin, and a mix of the two fluorescent secondary antibodies, with three washes in PBS-BSA after each step.

Statistical analysis. The Wilcoxon rank sum statistical test was used to compare differences in the mortality rates between groups of mice. For the other data, statistical analysis was assessed by analysis of variance (ANOVA) followed by Student's $t$-test. In all cases, $P<0.05$ was considered statistically significant.

\section{RESULTS}

\section{Virulence of S. schenckii isolates}

Isolates of $S$. schenckii were examined for their virulence in C57BL/6 mice inoculated intravenously. The survival curves demonstrated that $100 \%$ of mice infected with isolates IPEC 15383 and 1099-18 succumbed before 29 days. The mortality rates for these two isolates were similar $(P>0.05)$. A high mortality rate was also observed for the environmental isolate (FMR 8337), but significantly lower $(P<0.05)$ (Fig. 1A). In contrast, all mice inoculated with yeasts from isolate IPEC 17943 survived the infection even after 45 days. Differences were also seen in the fungal burden, determined by retro-culture from the organs of infected C57BL/6 mice. As shown in Fig. 1(B), the highest values were obtained for isolate IPEC 15383, followed by isolates 1099-18 and FMR 8337, but these values were not statistically different. In contrast, isolate IPEC 17943 differed significantly from the others, producing a very low fungal burden in the organs of infected mice.

\section{Macroscopic aspects of the organs from the infected mice and histopathology}

A particular dissemination pattern was observed in mice infected with isolate IPEC 17943. The livers showed normal macroscopic aspect (Fig. 2A; white arrow) while osteoarticular lesions were observed (Fig. 2B; black arrow) as well as nodular lesions along the tail (Fig. 2B; black arrowhead). Moreover, these lesions totally regressed within 120 days post-inoculation (data not shown). In contrast, at day 10 post-inoculation, diffuse nodular lesions were grossly evident on the liver of mice infected with the three other isolates (Fig. 2C, D and E; white arrows) as well as splenomegaly (Fig. 2F; white arrowhead), whereas cutaneous and osteoarticular lesions were absent along the tail of these mice.

Histopathological analysis of livers from IPEC 15383- or 1099-18-infected mice (Fig. 3A, B) revealed similar features, with numerous and large inflammatory infiltrates. Moreover, yeast cells assembled in dense clusters were easily observed (Fig. 3E, F). Frequently, inflammatory infiltrates produced in 1099-18-infected mice were located around branches of the portal vein and in parenchyma located between the portal triads and central veins of the hepatic lobule (Fig. 3B). Infection with FMR 8337 produced inflammatory infiltrates similar in size to those observed for mice infected by 1099-18 or IPEC 15383, but less numerous (Fig. 3C). Additionally, yeast cells were less abundant, although cluster formation was not rare (Fig. 3G). Livers from IPEC 17943-infected mice showed smaller diffuse inflammatory infiltrates, formed by neutrophils and mononuclear cells, located at the connective tissue of periportal space (Fig. 3D). Yeast cells were also observed, but cluster formation was rare (Fig. $3 \mathrm{H}$ ).

Histopathological analysis of lungs, spleens and kidneys of the mice infected with the four isolates were also performed. These organs from IPEC 15383-, 1099-18- or FMR 8337-infected mice revealed inflammatory infiltrates associated with the presence of yeast cells, in contrast to the organs of mice infected with IPEC 17943, which showed neither serious damage nor the presence of yeast cells (data not shown). In addition, the damage caused by the fungal infection in lungs, spleens and kidneys of mice infected was lower than that caused in the liver.

\section{Interaction of yeast cells of different S. schenckii strains with fibronectin}

Previous studies demonstrated that $S$. schenckii yeast cells adhere to fibronectin in a dose-dependent manner and that 


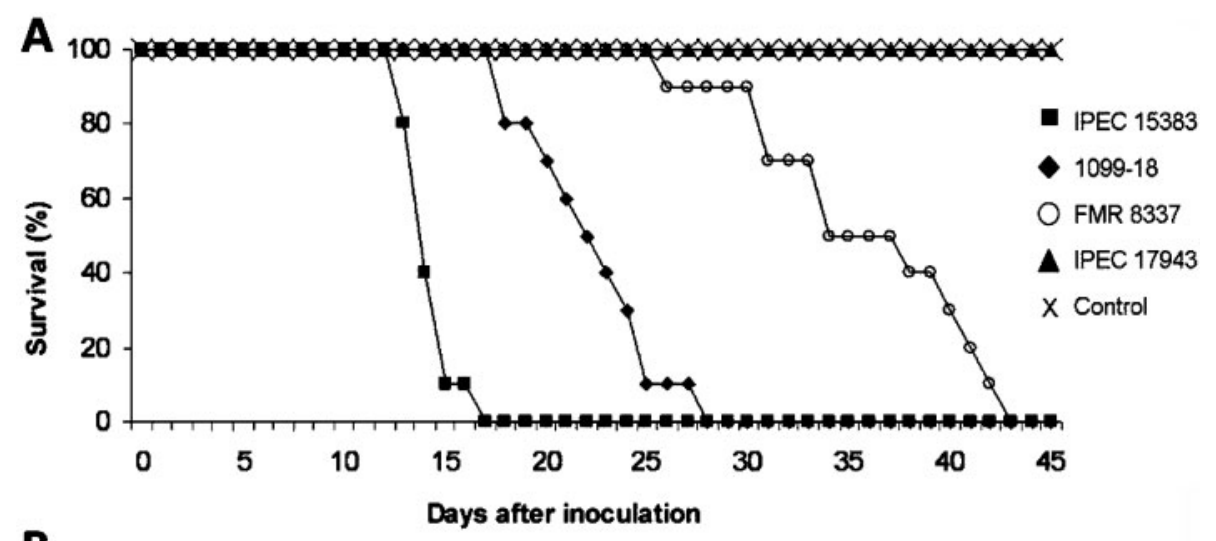

B

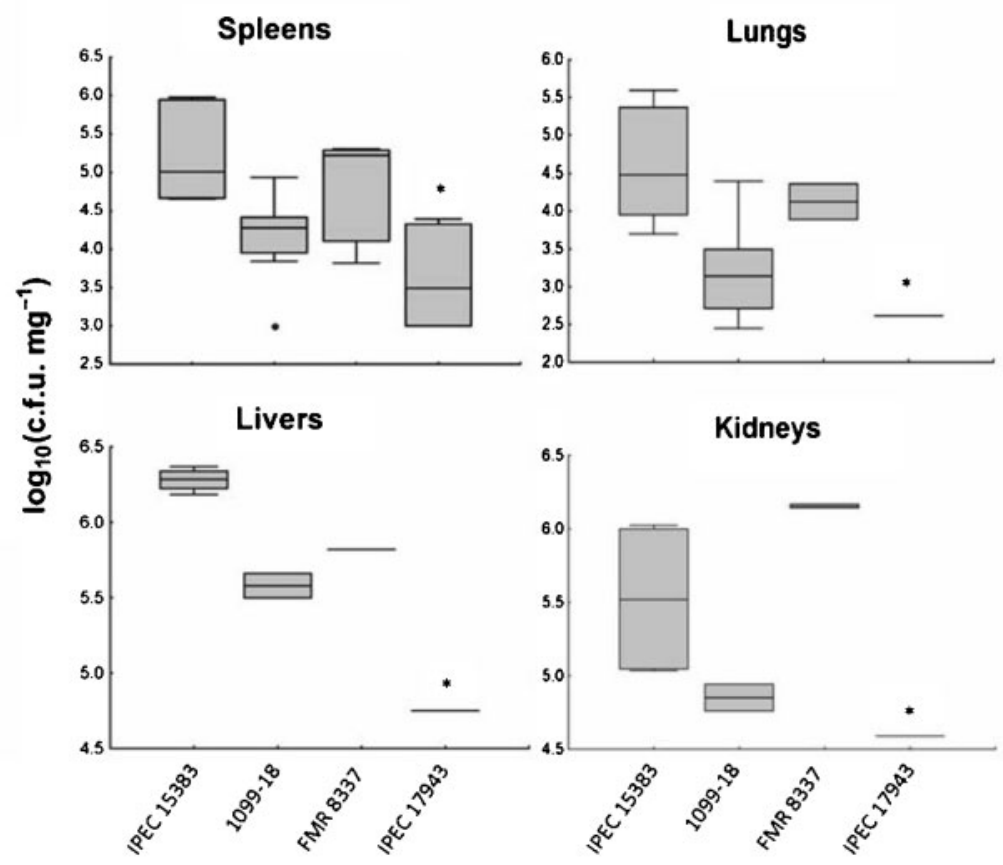

Fig. 1. Pathogenicity pattern of the yeast phase of four $S$. schenckii isolates. (A) Survival curves for C57BL/6 mice intravenously inoculated with $5 \times 10^{6}$ yeast cells of each isolate. (B) Fungal load in the spleens, lungs, livers and kidneys of individual mice sacrificed at day 10 post-inoculation. * $P<0.05$ (ANOVA).

this is a key step for crossing of the endothelial barrier (Lima et al., 1999, 2001, 2004; Figueiredo et al., 2007). The binding of fibronectin to yeast cells of the four isolates was therefore evaluated by flow cytometry. All isolates were able to interact with fibronectin (Fig. 4), and incubation of the cells with a 10-fold excess of the unlabelled ligand prior to the addition of the FITC-fibronectin demonstrated the specificity of the binding (Fig. 4). Interestingly, the least virulent isolate (IPEC 17943) in the murine model of disseminated sporotrichosis also showed the lowest fibronectin-binding capacity, with a mean fluorescence intensity value of 27.18 , which was significantly lower $(P<0.05)$ than that observed for isolates IPEC 15383, 1099-18 and FMR 8337 (mean fluorescence values of 51.31, 49.06 and 50.07, respectively).

\section{Identification of adhesins to fibronectin}

To ascertain adhesin expression at the cell surface of $S$. schenckii, cell wall extracts were prepared from the four isolates and further analysed by Western blotting. The SDS-PAGE protein profile for each extract showed differences between the isolates (Fig. 5A). The separated proteins were electroblotted onto nitrocellulose membranes and immunodetected with human fibronectin and anti-fibronectin polyclonal antibody (Fig. 5B) in order to identify surface adhesins. Several putative adhesins for fibronectin were observed and their expression varied among the four isolates. A similar adhesin pattern was observed for the isolates IPEC 15383 and 1099-18, with five major reactive bands corresponding 


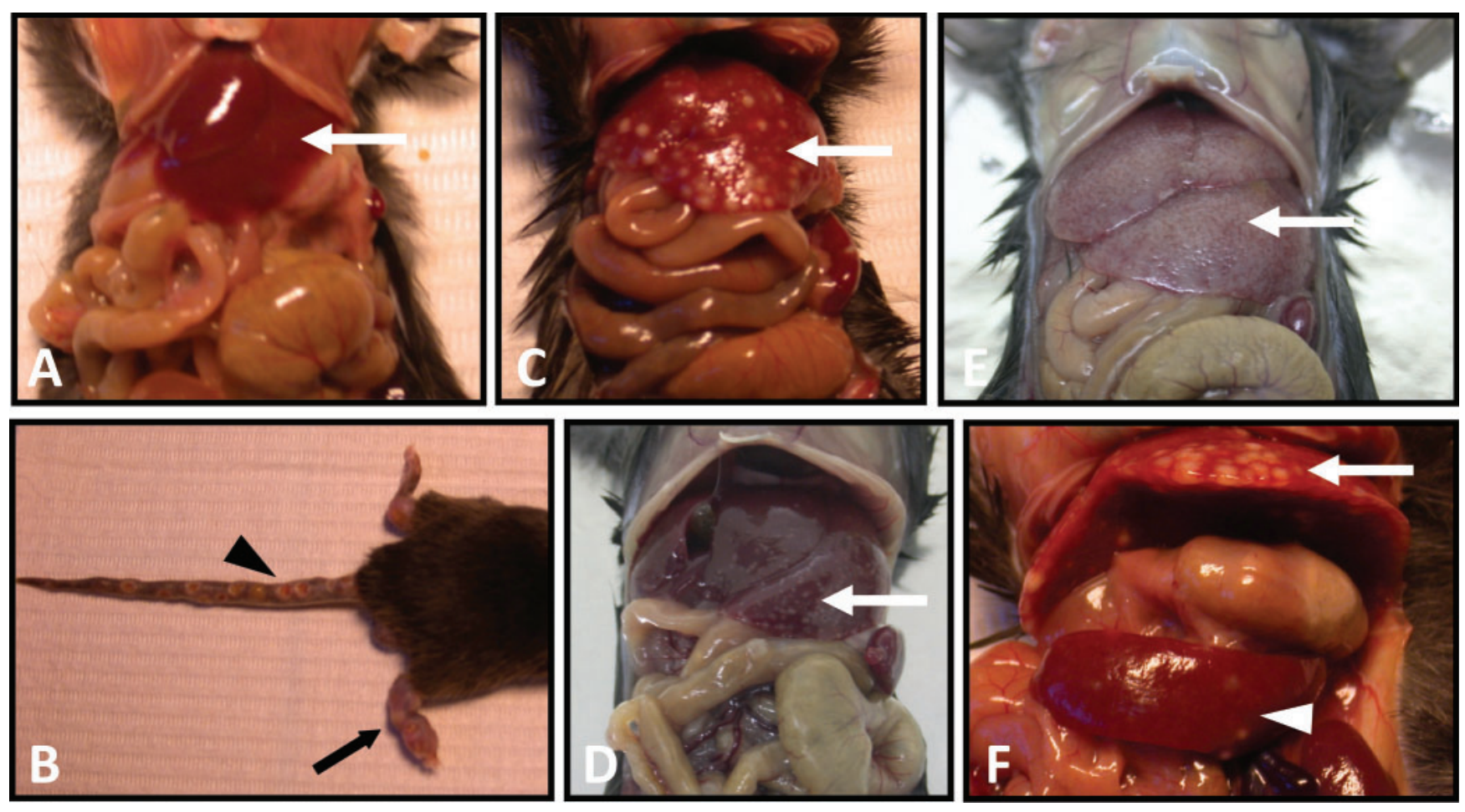

Fig. 2. Macroscopic examination of the organs of C57BL/6 mice infected with yeast cells of isolates IPEC 17943 (A, B), FMR 8337 (C, F), 1099-18 (D) or IPEC 15383 (E) and sacrificed at day 10 post-inoculation. Note the aspect of the liver (A, C, D, E and $\mathrm{F}$; white arrow) and the presence of splenomegaly ( $F$; white arrowhead). Mice infected with isolate IPEC 17943 also showed disseminated cutaneous lesions (B; black arrowhead) associated with osteoarticular sporotrichosis (B; black arrow).

to fibronectin-binding proteins of $92,70,55,44$ and $37 \mathrm{kDa}$. For the FMR 8337 isolate, three fibronectinbinding proteins were revealed corresponding to 152, 67 and $50 \mathrm{kDa}$ proteins, while a single positive band of
$67 \mathrm{kDa}$ was detected for the IPEC 17943 isolate. Negative controls were performed by the exclusion of the ligand or the anti-rabbit IgG HRP-conjugate (lanes 5 and 6, Fig. 5B).
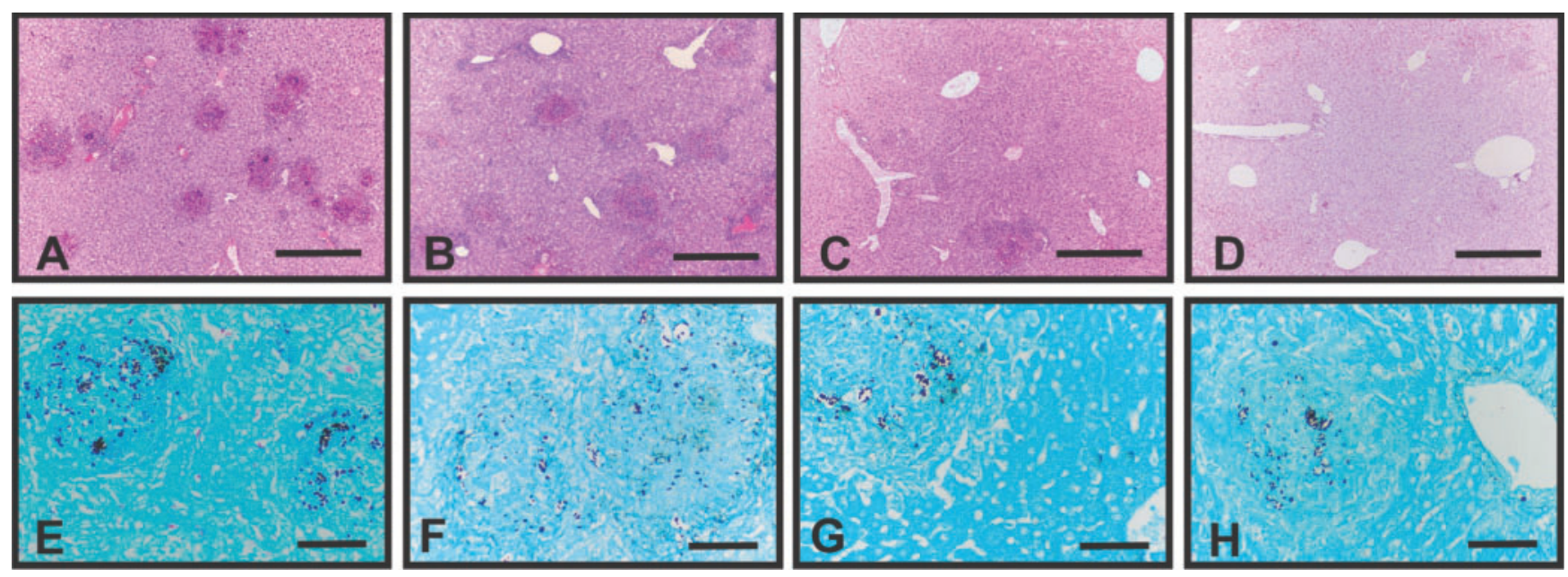

Fig. 3. Histopathology of the livers of C57BL/6 mice infected with yeast cells of S. schenckii isolates IPEC 15383 (A, E), 1099-18 (B, F), FMR 8337 (C, G) and IPEC 17943 (D, H). Sections of the livers were stained with periodic acid/Schiff (A-D) or modified Gomori's methenamine silver nitrate $(E-H)$. Bars: 250 nm (A-D); 50 nm (E-H). 


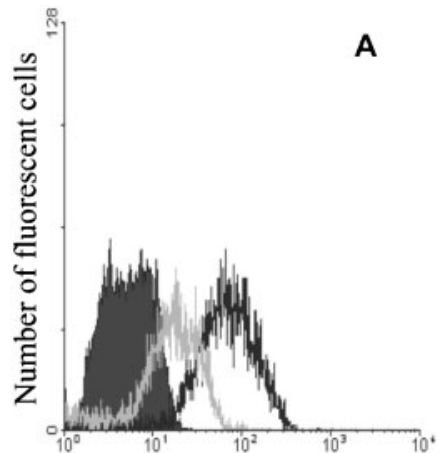

Fluorescence intensity

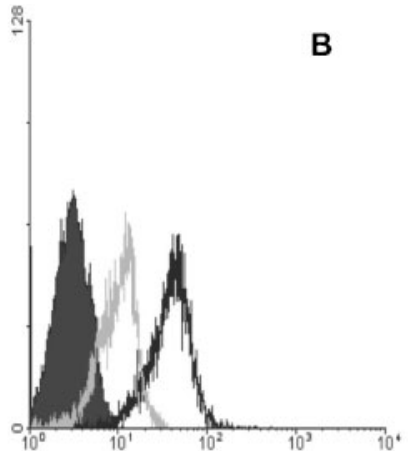

Fluorescence intensity

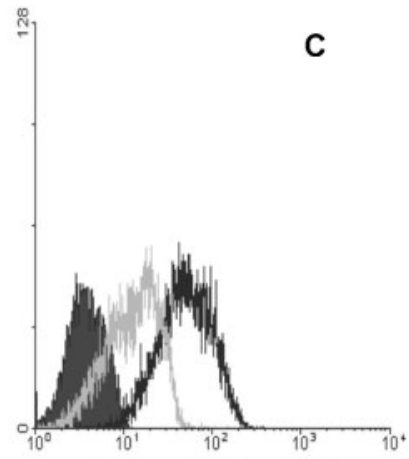

Fluorescence intensity

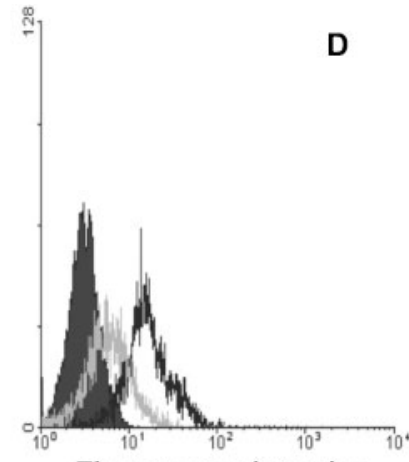

Fluorescence intensity

Fig. 4. Flow cytometry analysis of the binding of fibronectin to yeast cells of $S$. schenckii. The cell surface fluorescence of yeast cells from isolates IPEC 15383 (A), 1099-18 (B), FMR 8337 (C) and IPEC 17943 (D) incubated with FITC-fibronectin alone is shown by the black-line curves; the grey-line curves correspond to the fluorescence of cells incubated with a 10-fold molar excess of the unlabelled ligand before addition of FITC-fibronectin. The shaded dark grey curves correspond to the controls performed by incubation of the cells without any ligand.

\section{Characterization and surface localization of the $70 \mathrm{kDa}$ adhesin}

Our group recently characterized a $70 \mathrm{kDa}$ antigen on the cell wall of $S$. schenckii which mediates adhesion of the fungus to the native subendothelial matrix. This protein was recognized by the monoclonal antibody mAb P6E7 (Nascimento et al., 2008).

After electrophoretic separation of proteins of the cell wall extracts and their transfer onto nitrocellulose membranes, immunodetection with mAb P6E7 and an anti-mouse IgG HRP-conjugate revealed the presence of the gp70 antigen in the four isolates tested (Fig. 5C). Strikingly, the molecular mass of the immunoreactive band was lower, $67 \mathrm{kDa}$, for isolates FMR 8337 and IPEC 17943 (lanes 3 and 4 , Fig. 5C). As a positive control we assayed the purified gp70 (lane 5, Fig. 5C) and the negative controls were performed by the exclusion of the mAb $\mathrm{P} 6 \mathrm{E} 7$ or the anti-mouse IgG HRP-conjugate (lanes 6 and 7, Fig. 5C).

The co-localization of the gp70 antigen and the fibronectin-binding proteins on the surface of $S$. schenckii was investigated in the less and highly virulent isolates, IPEC 17943 and IPEC 15383. As revealed by confocal microscopy, the mAb P6E7 and fibronectin had similar binding sites at the surface of S. schenckii (Fig. 6C, G). These results showed that the co-localization of gp70 with the fibronectin-binding proteins in both isolates correlates with the Western-blot findings. Interestingly, binding sites only revealed for fibronectin (red points) were observed for the IPEC 15383 isolate (Fig. 6C), suggesting the presence of other adhesins besides gp70 on the fungus surface.

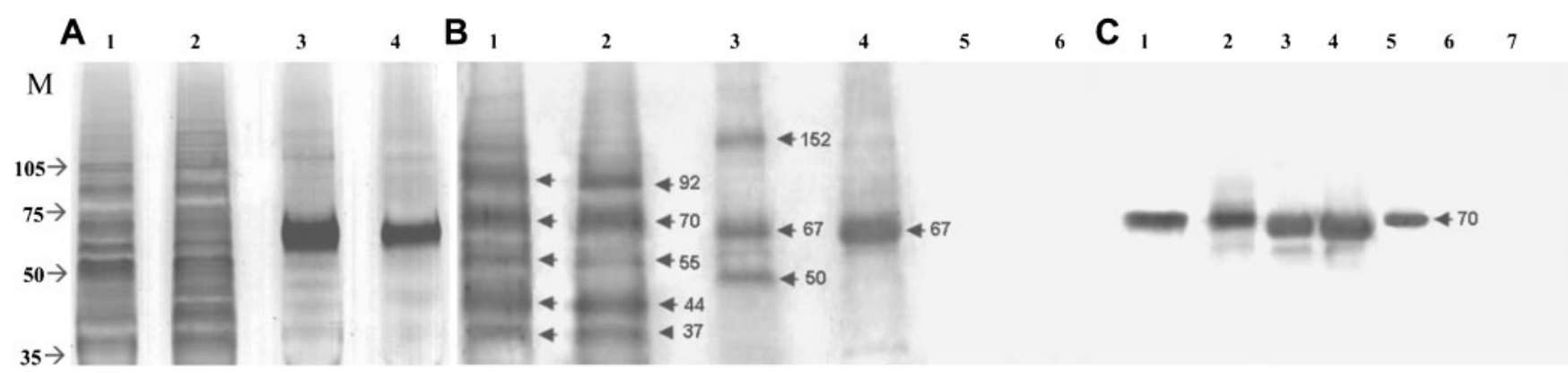

Fig. 5. SDS-PAGE and Western-blot analysis of $S$. schenckii cell wall extracts. Lanes 1-4 correspond to cell wall extracts from isolates IPEC 15383, 1099-18, FMR 8337 and IPEC 17943, respectively. (A) SDS-PAGE analysis of the cell wall extracts on a $10 \%$ polyacrylamide gel. $(B, C)$ Western-blot analysis of the cell wall extracts probed with human fibronectin (B) or with mAb P6E7 (C). In (B), lanes 5 and 6 are the controls performed by omission of fibronectin or the anti-fibronectin immune serum, respectively. In (C), lane 5 is a positive control with purified gp70 probed with the mAb P6E7, and lanes 6 and 7 are negative controls performed by omission of the mAb P6E7 or the anti-mouse IgG HRP conjugate, respectively. 

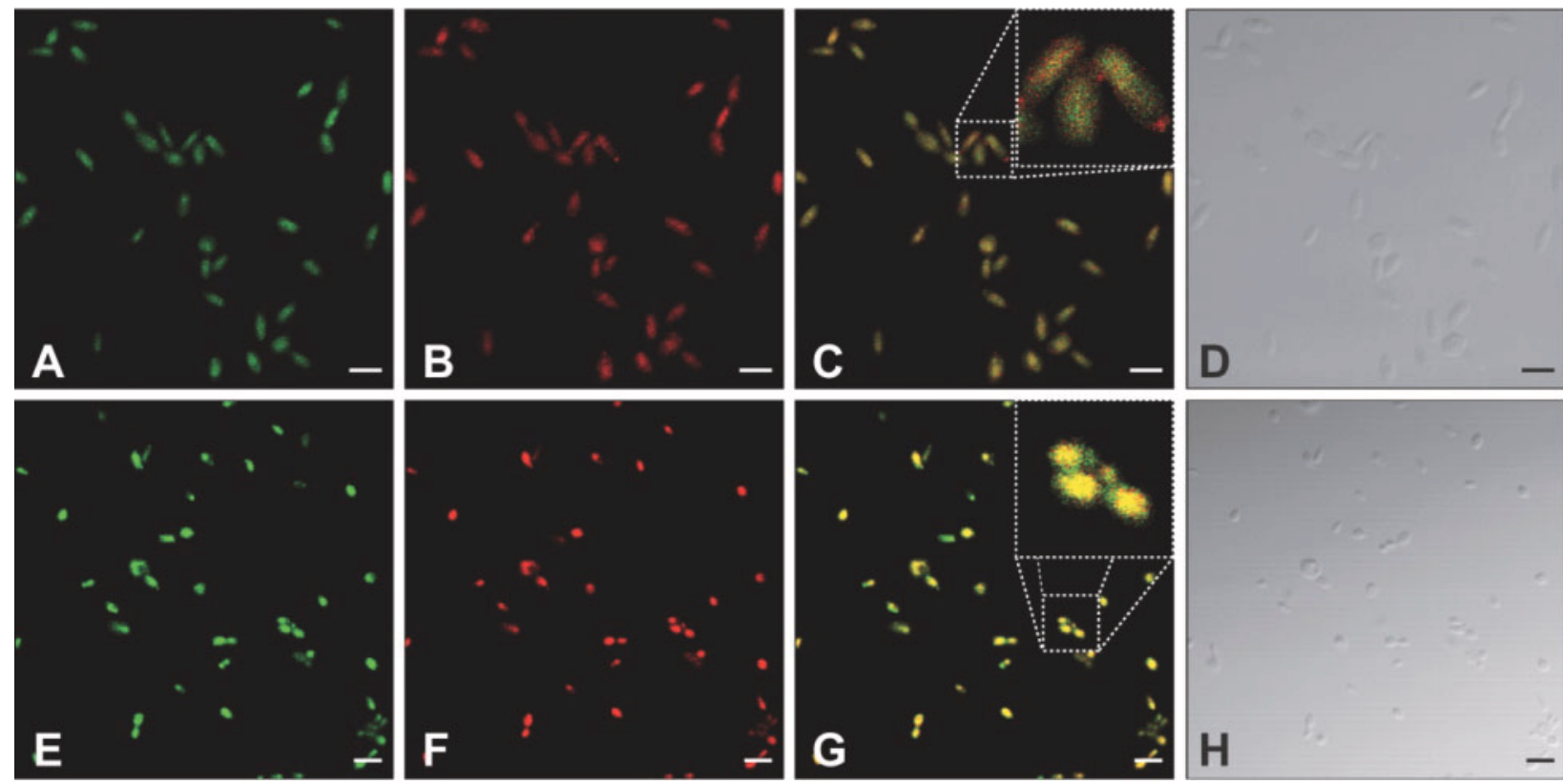

Fig. 6. Confocal microscopy of the binding of $m A b$ P6E7 (A, E) and fibronectin (B, F) to $S$. schenckii yeast cells from isolates IPEC $15383(A-D)$ or IPEC $17943(E-H)$. (C) and $(G)$ are the merged images resulting from successive incubations of the yeast cells with mAb P6E7, fibronectin, rabbit anti-human fibronectin and a mix of the two fluorescent secondary antibodies; the same fields visualized by differential interference contrast (DIC) are represented in (D) and (H). Insets: digital zoom of merged images. Note the stronger red fluorescence in the merged image of IPEC 15383 (C) compared to that of IPEC 17943 (G). Controls were performed using a normal rabbit serum (at 1:50 dilution) or an irrelevant anti-carcinoembryonic antigen (antiCEA; $100 \mu \mathrm{g} \mathrm{ml}^{-1}$ ) mAb instead of the primary antibody. Bars: $8 \mathrm{~nm}$.

Accordingly, several positive bands for fibronectin were revealed in the Western-blot analysis for this isolate (lane 1, Fig. 5B). Conversely, almost no red points were seen in the merged image for isolate IPEC 17943 (Fig. 6G), suggesting that the $67 \mathrm{kDa}$ variant of gp70 revealed by Western blotting is the major adhesin expressed on the cell surface of this isolate (lane 4, Fig. 5B).

\section{DISCUSSION}

The outcome of the host-pathogen interactions is determined by the amount of damage caused to the host. Host damage can result from direct action of the microorganism and/or the host response (Pirofski \& Casadevall, 2008). The microbial factors that can lead to host damage are known as virulence factors/regulators. Some of them have been identified and characterized in several fungal pathogens and correspond to molecules involved in adherence, host protein hydrolysis or immune response modulation, such as $\mathrm{BAD}-1$ from Blastomyces dermatitidis (Brandhorst et al., 1999), the secreted aspartyl proteinases from Candida albicans (Albrecht et al., 2006) and the melanin (Rosas et al., 2001) and capsule (Idnurm et al., 2005) of Cryptococcus neoformans. Regarding sporotrichosis, diverse clinical manifestations have been described, including lymphocutaneous, fixed cutaneous, disseminated cutaneous and extracutaneous forms (LopesBezerra et al., 2006). The variety of clinical presentations of the disease could be due at least in part to variations in the expression of virulence factors/regulators between $S$. schenckii isolates. Some S. schenckii genotypes seem to be associated with particular clinical manifestations (Maia et al., 2006; Kong et al., 2006). However, the intrinsic virulence factors of this pathogen remain unclear.

In the present work, the virulence in C57BL/6 mice, an animal model previously developed in our laboratory (Fernandes et al., 2000) and validated by other groups (Fernandes et al., 2008), and adherence capacity to fibronectin of several S. schenckii isolates were compared. The data obtained demonstrated that $S$. schenckii isolates recovered from different clinical forms of sporotrichosis and one environmental isolate showed distinct virulence levels in a murine model. Furthermore, no direct relationship between virulence and the clinical or environmental origin of the isolates was observed. This observation is also supported by the comparative virulence of several other clinical and environmental isolates (data not shown). Here, the most virulent isolates were recovered from patients with an extracutaneous form (isolate IPEC 15383) and a lymphocutaneous form (isolate 1099-18) of sporotrichosis. Interestingly, all mice infected with the IPEC 17943 isolate showed articular lesions that totally regressed in 120 days. 
These results diverge from those of previous papers, which reported that only systemic isolates were capable of causing systemic infection in mice (Tachibana et al., 1998). Kong et al. (2006) reported that isolates recovered from a disseminated form of sporotrichosis were more virulent in mice than those from lymphocutaneous and fixed cutaneous sporotrichosis. Our present results indicate that all S. schenckii isolates have an intrinsic pathogenicity, but distinct dissemination patterns were observed from one isolate to another. Furthermore, the isolates FMR 8337 and IPEC 17943 were clustered within a major monophyletic clade in a previous study (Marimon et al., 2006), but in the present study they showed distinct virulence levels in the murine model. Further studies involving markers/genes related to virulence are required to clarify the differences in the pathogenic behaviour of genetically related strains.

The adhesion capacity of micro-organisms is thought to play an important role in the infectious process. Previously, our group reported that $S$. schenckii adhered to fibronectin and laminin in soluble and immobilized forms (Lima et al., 1999, 2001, 2004) and that this is a key step for transposition of the endothelial barrier (Figueiredo et al., 2007). Here, the capacity of different isolates to bind fibronectin was investigated. All isolates were able to interact with fibronectin. However, the least virulent isolate (IPEC 17943) also exhibited the lowest capacity to interact with fibronectin as shown by flow cytometry. Similarly, different authors have reported a positive correlation between adhesion of fungal pathogens and virulence. For example, pathogenic strains of Aspergillus fumigatus bound significantly more fibronectin than non-pathogenic strains (Wasylnka \& Moore, 2000) and, among different strains of $P$. brasiliensis, the most virulent ones showed a stronger adherence to epithelial cells (Mendes-Giannini et al., 2006; Hanna et al., 2000).

Although the interaction between S. schenckii and fibronectin has already been described (Lima et al., 2001) the adhesins responsible for this interaction remained unknown. Recently, our group characterized a $70 \mathrm{kDa}$ protein on the cell wall of $S$. schenckii which mediates adhesion of the fungus to the native subendothelial matrix (Nascimento et al., 2008); likewise, Ruiz-Baca et al. (2008) described a $S$. schenckii cell surface protein with a similar molecular mass that seems to mediate adhesion of the fungus to a dermal extracellular matrix. Here, we investigated the presence of this protein, with adhesive properties, at the surface of each isolate. All the isolates tested expressed this protein at their surface. However, a slightly lower molecular mass $(67 \mathrm{kDa})$ was observed for the protein from isolates FMR 8337 and IPEC 17943; this might be related to differences in glycosylation. Strikingly, the least virulent isolate (IPEC 17943), which expressed only one fibronectin-binding protein (the $67 \mathrm{kDa}$ variant of gp70), had the lowest binding capacity to this extracellular matrix protein. Moreover, the most virulent isolates (IPEC 15383 and 1099-18), which showed higher adhesive capacity, expressed at least four fibronectinbinding proteins besides gp70.

Together, these results suggest that virulence of $S$. schenckii isolates is related, at least in part, to the expression of adhesins for fibronectin at the fungal surface. Nevertheless, besides the expression of adhesins, other virulence factors, which remain to be determined, may also be involved in the dissemination process. This work not only provides new insights regarding the pathogenesis of sporotrichosis, by presenting evidence for a relationship between adhesin expression and pathogenicity. It also reports adhesins for fibronectin at the surface of $S$. schenckii yeast cells.

\section{ACKNOWLEDGEMENTS}

The authors are grateful to Dr Geraldo Moura Batista Pereira for providing access to the FACScan flow cytometer. L.M.L.B. is a research fellow of Conselho Nacional de Desenvolvimento Científico e Tecnológico (CNPq, Brazil). This work was supported by Fundação de Amparo a Pesquisa do Estado do Rio de Janeiro (FAPERJ) grants E-26/171521/04 and E-26/171557/06.

\section{REFERENCES}

Albrecht, A., Felk, A., Pichova, I., Naglik, J. R., Schaller, M., De Groot, P., MacCallum, D., Odds, F. C., Schafer, W. \& other authors (2006). Glycosylphosphatidylinositol-anchored proteases of Candida albicans target proteins necessary for both cellular processes and host-pathogen interactions. J Biol Chem 281, 688-694.

Bjellqvist, B., Pasquali, C., Ravier, F., Sanchez, J. C. \& Hochstrasser, D. (1993). A nonlinear wide-range immobilized $\mathrm{pH}$ gradient for twodimensional electrophoresis and its definition in a relevant $\mathrm{pH}$ scale. Electrophoresis 14, 1357-1365.

Brandhorst, T. T., Wuthrich, M., Warner, T. \& Klein, B. (1999). Targeted gene disruption reveals an adhesin indispensable for pathogenicity of Blastomyces dermatitidis. J Exp Med 189, 1207-1216.

Fernandes, K. S., Coelho, A. L., Lopes Bezerra, L. M. \& Barja-Fidalgo, C. (2000). Virulence of Sporothrix schenckii conidia and yeast cells, and their susceptibility to nitric oxide. Immunology 101, 563-569.

Fernandes, K. S., Neto, E. H., Brito, M. M., Silva, J. S., Cunha, F. Q. \& Barja-Fidalgo, C. (2008). Detrimental role of endogenous nitric oxide in host defence against Sporothrix schenckii. Immunology 123, 469479.

Figueiredo, C. C., Deccache, P. M., Lopes-Bezerra, L. M. \& Morandi, V. (2007). TGF- $\beta 1$ induces transendothelial migration of the pathogenic fungus Sporothrix schenckii by a paracellular route involving extracellular matrix proteins. Microbiology 153, 2910-2921.

Grocott, R. G. (1955). A stain for fungi in tissue sections and smears using Gomori's methenamine-silver nitrate technique. Am J Clin Pathol 25, 975-979.

Hanna, S. A., Monteiro da Silva, J. L. \& Mendes-Giannini, M. J. S. (2000). Adherence and intracellular parasitism of Paracoccidioides brasiliensis in Vero cells. Microbes Infect 2, 877-884.

Idnurm, A., Bahn, Y. S., Nielsen, K., Lin, X., Fraser, J. A. \& Heitman, J. (2005). Deciphering the model pathogenic fungus Cryptococcus neoformans. Nat Rev Microbiol 3, 753-764.

Klis, F. M., de Jong, M., Brul, S. \& de Groot, P. W. (2007). Extraction of cell surface-associated proteins from living yeast cells. Yeast 24, 253-258. 
Köhler, G. \& Milstein, C. (1975). Continuous cultures of fused cells secreting antibody of redefined specificity. Nature 256, 495-497.

Kong, X., Xiao, T., Lin, J., Wang, Y. \& Chen, H. D. (2006). Relationships among genotypes, virulence and clinical forms of Sporothrix schenckii infection. Clin Microbiol Infect 12, 1077-1081.

Laemmli, U. K. (1970). Cleavage of structural proteins during the assembly of the head of bacteriophage T4. Nature 227, 680-685.

Lima, O. C., Figueiredo, C. C., Pereira, B. A., Coelho, M. G., Morandi, V. \& Lopes-Bezerra, L. M. (1999). Adhesion of the human pathogen Sporothrix schenckii to several extracellular matrix proteins. Braz J Med Biol Res 32, 651-657.

Lima, O. C., Figueiredo, C. C., Previato, J. O., Mendonça-Previato, L., Morandi, V. \& Lopes-Bezerra, L. M. (2001). Involvement of fungal cell wall components in adhesion of Sporothrix schenckii to human fibronectin. Infect Immun 69, 6874-6880.

Lima, O. C., Bouchara, J. P., Renier, G., Marot-Leblond, A., Chabasse, D. \& Lopes-Bezerra, L. M. (2004). Immunofluorescence and flow cytometry analysis of fibronectin and laminin binding to Sporothrix schenckii yeast cells and conidia. Microb Pathog 37, 131-140.

Lopes-Bezerra, L. M., Schubach, A. \& Costa, O. R. (2006). Sporothrix schenckii and sporotrichosis. An Acad Bras cienc 78, 293-308.

Maia, D. C., Sassa, M. F., Placeres, M. C. \& Carlos, I. Z. (2006). Influence of Th1/Th2 cytokines and nitric oxide in murine systemic infection induced by Sporothrix schenckii. Mycopathologia 161, 11-19.

Marimon, R., Gené, J., Cano, J., Trilles, L., Dos Santos Lazéra, M. \& Guarro, J. (2006). Molecular phylogeny of Sporothrix schenckii. J Clin Microbiol 44, 3251-3256.

Mendes-Giannini, M. J., Andreotti, P. F., Vincenzi, L. R., da Silva, J. L., Lenzi, H. L., Benard, G., Zancope-Oliveira, R., de Matos Guedes, H. L. \& Soares, C. P. (2006). Binding of extracellular matrix proteins to Paracoccidioides brasiliensis. Microbes Infect 8, 1550-1559.

Nascimento, R. C., Espíndola, N. M., Castro, R. A., Teixeira, P. A., Loureiro y Penha, C. V., Lopes-Bezerra, L. M. \& Almeida, S. R. (2008). Passive immunization with monoclonal antibody against a
70-kDa putative adhesin of Sporothrix schenckii induces protection in murine sporotrichosis. Eur J Immunol 38, 3080-3089.

Patti, J. M., Allen, B. L., McGavin, M. J. \& Hook, M. (1994). MSCRAMM-mediated adherence of microorganisms to host tissues. Annu Rev Microbiol 48, 585-617.

Pirofski, L. A. \& Casadevall, A. (2008). The damage-response framework of microbial pathogenesis and infectious diseases. $A d v$ Exp Med Biol 635, 135-146.

Prophet, E. B., Mills, B., Arrington, J. B. \& Sobin, L. H. (1992). Laboratory Methods in Histotechnology, Chapter 18: Carbohydrates. Washington DC: Armed Forces Institute of Pathology, American Registry of Pathology.

Rosas, A. L., Nosanchuk, J. D. \& Casadevall, A. (2001). Passive immunization with melanin-binding monoclonal antibodies prolongs survival of mice with lethal Cryptococcus neoformans infection. Infect Immun 69, 3410-3412.

Ruiz-Baca, E., Toriello, C., Pérez-Torres, A., Sabanero-López, M., Villagómez-Castro, J. C. \& López-Romero, E. (2008). Isolation and some properties of a glycoprotein of $70 \mathrm{kDa}(\mathrm{Gp} 70)$ from the cell wall of Sporothrix schenckii involved in fungal adherence to dermal extracellular matrix. Med Mycol 47, 185-196.

Tachibana, T., Matsuyama, T. \& Mitsuyama, M. (1998). Characteristic infectivity of Sporothrix schenckii to mice depending on routes of infection and inherent fungal pathogenicity. Med Mycol 36, 21-27.

Tachibana, T., Matsuyama, T., Ito, M. \& Mitsuyama, M. (2001). Sporothrix schenckii thermo-intolerant mutants losing fatal visceral infectivity but retaining high cutaneous infectivity. Med Mycol 39, 295-298.

Wasylnka, J. A. \& Moore, M. M. (2000). Adhesion of Aspergillus species to extracellular matrix proteins: evidence for involvement of negatively charged carbohydrates on the conidial surface. Infect Immun 68, 3377-3384.

Edited by: K. Kuchler 